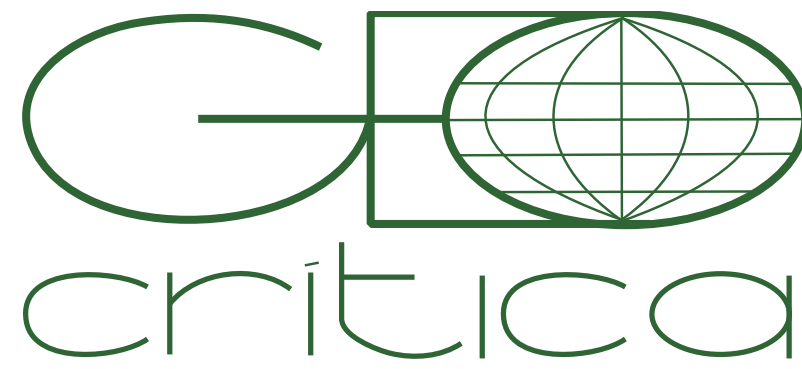

Scripta Nova

Revista Electrónica de Geografía y Ciencias Sociales

Universitat de Barcelona

ISSN: $1138-9788$

Vol. 25, Núm. 2 (2021), 57-73

\title{
LA FRONTERIZACIÓN \\ DE LA PERIFERIA URBANA DE MADRID
}

\author{
Candela Morado \\ Investigadora predoctoral en la Universidad Politécnica de Madrid (UPM) y el Consejo Superior de \\ Investigaciones Científicas (CSIC) \\ candela.morado@gmail.com
}

Recibido: 09 octubre 2020; Devuelto para correcciones: 01 marzo 2021; Aceptado: 04 mayo 2021

\section{La fronterización de la periferia urbana de Madrid (Resumen)}

En este artículo abordamos la formación de territorios urbanos fronterizos a través del análisis de caso de La Cañada Real Galiana. A partir de un estudio de corte cualitativo centrado en entrevistas, derivas y análisis documental, desplegaremos cuatro órdenes de análisis: jurídico, territorial, mediático y del discurso encarnado. Así, exploraremos cómo se construyen y sostienen los límites físicos, simbólicos y temporales de la ciudad de Madrid, asumiendo que la Cañada Real ejemplifica su límite este-sur, pero también el límite de lo civilizado con un espacio sin ley ni orden. El concepto geográfico y epistémico de "frontera" será caracterizado a través de cuatro elementos: los sucesivos diseños urbanos, los bolardos, el barro y los escombros. En suma, articularemos un relato que desvela la Cañada Real como un espacio fronterizo capaz de activar un debate profundo sobre el desorden, la segregación, el estigma y la quiebra de un posible horizonte de futuro.

Palabras clave: informalidad urbana; marginalidad; desigualdad urbana; frontera.

\section{The bordering of the urban periphery of Madrid (Abstract)}

In this paper we address the formation of urban border territories through the case study of Cañada Real Galiana. Through a qualitative study focused on interviews, drifts and documentary analysis, we will deploy four analytical orders: legal, territorial, media and embodied discourse. Thus, we will explore how the physical, symbolic and temporal border of the city of Madrid are built and sustained, assuming that the Cañada Real exemplifies its east-south limit, but also the limit of the civilized with a space without law or order. The geographical and epistemic concept of "border" is characterized by four elements: successive urban designs, bollards, mud and rubble. In short, we will articulate a story that reveals the Cañada Real as a border area capable of activating a deep debate about disorder, segregation, stigma and rupture of a possible future horizon. Keywords: urban informality; marginality; urban inequality; border. 
F. sale temprano de casa con sus tres hijas, como todas las mañanas. Vive en el sector IV de la Cañada Real. Lleva a las dos mayores agarradas de una mano y la pequeña cogida en brazos, no hay aceras por las que poder rodar cómodamente un carrito y los coches pasan demasiado cerca. La primera parada es cinco puertas más allá en casa de un familiar para dejar a la más pequeña. Un par de puertas después recoge a J., el hijo de su vecina. Pronto entran en el sector $\mathrm{V}$ y tras recorrer kilómetro y medio por la vía llegan al CEIP El Olivar. Allí deja a sus dos hijas y a J. con algo de prisa. F. camina otro kilómetro más hasta la estación de metro de Rivas Urbanizaciones. En seis minutos llega a Vicálvaro y toma un cercanías en dirección Atocha. Transbordo y cambio de la línea C2 a la C5 hasta Puente de Alcocer, la parada más cercana al Polideportivo donde trabaja unas horas limpiando las instalaciones. Antes de acostumbrarse a este trayecto, cuando era más joven, realizó otro gran desplazamiento. Cruzó el Estrecho desde Tánger hasta la costa gaditana. Desde Cádiz hasta un pueblo de Almería, donde estuvo viviendo unos meses. Finalmente llegó a Madrid, pero aún tuvo que mudarse un par de veces más hasta llegar a la casa donde vive ahora. Ya son 11 años como vecina de la Cañada Real.

Hablar de la periferia implica hablar de desplazamientos, a la ciudad y en la ciudad. También de desplazamientos desde países periféricos separados de los supuestos polos de progreso. El problema del desplazamiento ha ocupado un lugar importante en los estudios sobre las ciudades desde el s. XIX, momento en el que se dieron traslados masivos por la rápida industrialización de algunas ciudades europeas. Como señala David Harvey, el desplazamiento "anida en el corazón de la urbanización dentro del sistema capitalista" $(2008,34)$. Hoy en día, relacionado con un abanico de procesos muy amplio, que van desde la gentrificación a la migración pasando por procesos de evacuación o desalojo, sigue manteniéndose viva como una preocupación central en los estudios urbanos contemporáneos esta cuestión que podemos entender como el "desacople entre personas y lugares" (Zeiderman 2016, 17), o el problema de las personas "fuera de lugar".

La promesa de "la ciudad que está por llegar" (Simone 2004), ha proporcionado históricamente, pero también hoy en nuestros días, un imaginario de esperanza de un futuro mejor para las personas que se desplazan a las periferias urbanas de grandes ciudades. Periferias alejadas (geográficamente o simbólicamente) de las condiciones materiales de los espacios centrales y principalmente receptoras de población atravesada por procesos de desplazamiento que se han quedado en el camino del desarrollo en favor de un proyecto de prosperidad (Ghannam 2002; Roy y AlSayyad 2004). Sin embargo, algunos académicos han denunciado que esa "urbanización planetaria" en curso contiene las semillas para una crisis global (Brenner 2013). En esta línea muchos autores visualizan un futuro caótico vinculado a la tendencia creciente hacia la vida urbana y la proliferación de periferias de crecimiento desordenado. Esta posición ha sido bien sintetizada por Mike Davis con su conocido trabajo sobre "ciudades miseria" (Davis 2006), cuestionado por ofrecer una visión del desarrollo urbano distópico que nos condena inexorablemente a un "exceso de habitantes" ("surplus humanity", Davis 2006, 174-198). En ese planteamiento se dibuja un futuro cercano en el que las ciudades están "tomadas" por espacios de pobreza crecientes que van ocupando territorio urbano provocando, entre otras cosas, la ansiedad por la inmigración. Un miedo que se materializa en la construcción de muros, pero también en la construcción de fronteras más 
sutiles que sirven de herramienta para profundizar en la exclusión (Roy 2005, 148; Zeiderman 2016, 194-207).

No podemos pensar en el proyecto de desarrollo urbano como un proceso capaz de ser inclusivo con todas las personas y áreas de la ciudad. Las periferias son partes consustanciales a la utopía moderna, que sólo puede lograrse marginando, empobreciendo y desplazando a las poblaciones más vulnerables (Bou 2018, 182; Holston 1989). La ciudad no sólo requiere de esos márgenes, sino que éstos forman parte consustancial de ella: son sus vertederos, sus mercados ilegales o sus espacios de pobreza. Como matiza Chantal Mouffe $(2000,12)$, se trata de un "afuera constitutivo", ya que no es un opuesto sino una condición de existencia. Ahora bien, al mismo tiempo que requiere de un afuera, este hace peligrar su delimitación interior fija y, de un modo más general, también pone en crisis la ciudad en tanto que proyecto universal, revelando sus límites, porosidades y fragilidades.

En este artículo nos proponemos reflexionar desde los intersticios de los regímenes territoriales, jurídicos, legales y sociales (Roy 2011). Para ello utilizaremos el concepto de frontera, para situarnos en el lugar específico donde las dinámicas periféricas de demarcación, tensión y resistencia se muestran particularmente evidentes. La frontera no es solo un lugar geográfico sino un locus epistémico, una manera de habitar y de relacionarse con la ciudad. En este sentido, nuestro objetivo es estudiar desde la periferia la formación de espacios fronterizos, caracterizando los procesos sociomateriales que los constituyen y sostienen, pues ahí es donde se agolpan sus contradicciones, tensiones y conflictos. Los espacios fronterizos se caracterizan por la densidad de enredos entre legalidad e ilegalidad, planificación y desorden, lujo y pobreza, accesibilidad y bloqueo, oportunidad y miseria. Como argumenta Achille Mbembe, en estos contextos las tensiones en juego pueden ser también temporales, ya que son determinantes a la hora de "cerrar el futuro para algunas personas y mantenerlo abierto para otras" (citado en Bou 2018, 182).

En suma, nos interrogamos sobre cómo se están construyendo y sosteniendo los límites sociomateriales y simbólicos de la ciudad de Madrid a través del caso de estudio de la Cañada Real Galiana. Partimos de la premisa de que el desarrollo urbano de este asentamiento informal está íntimamente ligado al de la capital, y ejemplifica no solo el límite geográfico este-sur de la ciudad, también la contraposición entre lo urbano, lo ordenado y "civilizado" con la no-ciudad, con un espacio "sin ley ni orden".

La Cañada Real constituye un caso muy excepcional de asentamiento informal por sus peculiaridades jurídicas y territoriales. Se sitúa en una de las nueve vías pecuarias principales que recorren de norte a sur la península para la actividad trashumante desde el s. XIII. Concretamente, el caso que nos ocupa corresponde a los 15 kilómetros de vía dentro de la Comunidad de Madrid, desde Coslada hasta Getafe. Comenzó a ocuparse en la década de 1960, pero más intensamente a partir de la década de 1990. Desde entonces ha sido una cuestión muy controvertida y en ella se articulan una pluralidad de perspectivas y posiciones en torno a las posibles soluciones a un problema que es tan social como ecológico y político.

Nos centraremos especialmente en la dimensión social y temporal de las materialidades en juego en la constitución de la Cañada Real como espacio límite, para enfatizar la importancia de entender la frontera no como un objeto dado sino como un conjunto de procesos que la constituyen (Mezzadra y Neilson 2013, 37). La frontera dibuja 
unos contornos complejos, difusos y en continua negociación, y a través de su análisis podremos reconstruir epistemológicamente lo urbano sin posicionarnos en el centro, en lo instituido o en lo normativo, sino allí donde estos límites se desdibujan.

Para ello, hemos diseñado una metodología que nos permite explorar las conexiones complejas que surgen entre los diferentes órdenes de análisis: jurídico, territorial, mediático y del discurso encarnado. En el primer orden, hemos evaluado el marco jurídico estatal y autonómico en el que se inserta el asentamiento, así como su evolución en el tiempo. En el segundo, hemos estudiado, a partir de la documentación cartográfica disponible, de fotografías aéreas y de derivas por el territorio, los patrones de asentamiento, así como su estructura y límites con especial detenimiento en los sectores II, IV y V. En el tercero, analizamos las publicaciones de los dos periódicos principales El País y El Mundo entre los años 2001 hasta 2016, con el objetivo de estudiar la creación de relatos dominantes. Por último, y con el objetivo de conocer el discurso encarnado de las personas que habitan la Cañada, hemos realizado 6 entrevistas semiestructuradas ( 4 a vecinos y 2 a trabajadoras de organizaciones presentes en el territorio) y dos derivas acompañadas de vecinas y trabajadoras.

Tras esta introducción, en la que hemos presentado el problema a tratar y dibujado un marco para abordarlo teóricamente, organizaremos los resultados de la investigación en dos partes. En una primera parte, expondremos un breve contexto histórico de la urbanización informal en Madrid, para analizar cuáles son las particularidades que despliega la Cañada Real. El estudio de este caso concreto nos llevará a proponer un desplazamiento conceptual de los estudios de periferia hacia la "fronterización" de la periferia. En una segunda parte, profundizaremos en el problema de la frontera urbana y trataremos de caracterizarla apoyándonos en cuatro elementos: los sucesivos diseños urbanos, los bolardos, el barro y los escombros. Estos cuatro elementos nos servirán para articular un relato sobre cómo se están dibujando los límites políticos, sociomateriales y simbólicos en la ciudad de Madrid, para profundizar en un debate sobre el desorden, la segregación, el estigma y la quiebra de un horizonte de futuro.

\section{La urbanización informal en Madrid: la fronterización de la periferia}

La historia de la ciudad de Madrid no se puede entender sin los barrios autoconstruidos de “casitas bajas". En la década de 1950 la capital, junto a otras grandes ciudades como Barcelona o Bilbao, sufrió un aluvión migratorio de las zonas rurales. Esta llegada masiva fue clave para la expansión económica de la década posterior, pero desbordó la capacidad de planificación de la ciudad que no ofrecía más alternativa habitacional que hacinadas viviendas en el centro o la ocupación de terrenos en zonas alejadas de la ciudad y también en zonas próximas al Ensanche y al río (Carabancheleando 2017, 16).

Estos barrios, con un crecimiento en su mayoría no planificado y habitados por personas humildes, eran tratados con desprecio durante la dictadura, y en ocasiones, incluso, como ocurrió con barrios como el de la Ventilla, se les creía "reductos de inmoralidad" (Carmona y Rodríguez 2007, 333). Como en otros puntos de la geografía, las malas condiciones de las infraestructuras y la cualidad no normativa de muchas de las actividades 
que se realizaban en ellos (ilegalidades o de "baja categoría") servían para justificar planes de extinción.

La primera gran operación contra el chabolismo empezó con los Decretos-ley de 1954 y el I Plan Nacional de Vivienda de 1955 (Carabancheleando 2017, 17). Se promovió la construcción de "poblados dirigidos", en los que las familias aportaban trabajo en la construcción con apoyo de un gabinete técnico (las domingueras), y "poblados de absorción" en régimen de alquiler en los alrededores de la ciudad con el objetivo de alojar a los emigrantes y eliminar el chabolismo a través de expandir la ciudad.

En 1957 se creó el Ministerio de Vivienda y se puso en marcha el Plan de Urgencia Social para la construcción de "vivienda subvencionada", de la mano del ministro Luis Arrese, que pretendía cambiar la política de vivienda en régimen de alquiler por la propiedad (con su conocido lema "un país de propietarios, no de proletarios"). En aquel momento ya se calculaba un número de chabolas mayor de 50.000, lo que suponía el 16,6\% del suelo residencial de Madrid (Carmona y Rodríguez 2007, 347; Sambricio 1999, 64-65). El plan tenía un doble propósito, por un lado, ser símbolo de prosperidad de la ciudad y, por otro, consolidar el negocio de las promociones de vivienda privada, clave en la consolidación del sector en los años posteriores. Sin embargo, estas promociones públicas, pronto se conocieron como el "chabolismo oficial” (Carabancheleando 2017,18) ya que además de ser insuficientes, no ofrecían unas condiciones sustancialmente mejores que las ofrecidas por la autoconstrucción: se trataba de viviendas también alejadas de los centros urbanos, de calidades muy deficientes, y con infraestructuras mínimas y precarias.

Por ello, a pesar de los esfuerzos por terminar con los barrios informales a través de un decreto específico (1957) que impedía la formación de asentamientos clandestinos, dictaba el derribo de chabolas y el desplazamiento de sus habitantes, muchos persistieron y se crearon otros nuevos, como Orcasitas o los alrededores de Puente de Vallecas, consolidando así la periferia sur de la ciudad. Aquellas formas de construcción de ciudad que fueron entendidas como marginales, provisionales o no propiamente parte constitutiva de la ciudad, tuvieron un papel fundamental en la absorción del crecimiento demográfico y en el diseño de la morfología de la ciudad (Vorms 2003).

Ya en democracia, dentro de las precarias zonas de "casitas bajas" se fueron tejiendo redes de apoyo mutuo y solidaridad que se convertirían en movimientos vecinales históricos que, tras años de protestas, consiguieron el compromiso de la administración con el Plan de Remodelación de Barrios (PRB). Se trataba de una fórmula novedosa en la que el vecindario por primera vez era protagonista de su propio proceso de trasformación, paralizando expulsiones, consiguiendo reubicaciones en el mismo barrio y decidiendo desde la implantación urbana a las calidades constructivas (Castells 1983; Rodríguez-Villasante et al. 2009). Se consiguieron de este modo la reconstrucción y mejora de casi 30 barrios de Madrid (Carmona y Rodríguez 2007, 356-357). En 1986, el porcentaje de familias residentes en asentamientos autoconstruidos había descendió al 9\% (casi la mitad que treinta años antes) pero de estos un 93\% eran familias gitanas (Álvarez-de Andrés 2020,13). Los asentamientos informales desde este momento pasaron a verse como pequeñas excepciones o anomalías casi exóticas. 
A finales de la década de los 90 y principios de los 2000 la urbanización informal se incrementó de nuevo por la llegada de migrantes para trabajar en sectores que estaban experimentando un gran crecimiento como la industria de la construcción. Ninguno de los dos planes que se diseñaron en ese periodo para luchar contra la urbanización marginal, ni el Consorcio para el Realojamiento de Población Marginal, ni el IRIS (Instituto de Realojamiento e Integración Social), incluyó a la Cañada Real. Además, más de la mitad de las demoliciones que se realizaron a partir de ellos se hicieron sin alternativa habitacional (Nogues 2010), por lo que la población desalojada terminaba en otros asentamientos vecinos, generando una cadena de reubicaciones sin soluciones que aportaran un asiento duradero. Es justamente en los primeros años del siglo XXI cuando la Cañada Real se posiciona como "el asentamiento informal más grande de Europa" (Aguilera 2017).

La periferia ha sido un concepto muy poderoso, principalmente, en estudios urbanos del llamado "Sur Global” (Caldeira 2000; Robinson 2005; Roy y AlSayyad 2004; Simone 2004; Bou 2018). Las periferias tienden a estar en los "sures" de las ciudades, pero la distancia de separación con respecto al centro no siempre es geográfica. Se tratan de espacios urbanos habitados desde la precariedad y excluidos tanto material como simbólicamente. Pero como señal Abdoumaliq Simone, esta exclusión también las puede dotar de potencialidad, pues en tanto que inconclusas, no planificadas o difíciles de controlar, también albergan un futuro más abierto $(2007,464)$. Por ello, a pesar de ser expresión de condiciones precarias, son teorizadas como espacios de esperanza, pues es precisamente la ausencia de recursos básicos la que puede impulsar la constitución de nuevas formas de "ciudadanía insurgente" que reclamen tanto un "derecho a la ciudad" como un "derecho a derechos" (Holston 2009, 245).

Si bien en un primer momento la urbanización informal de las periferias obreras madrileñas era una táctica de personas empobrecidas que afectaba a sectores diversos de la sociedad que lideraron luchas históricas por el derecho a la vivienda, a partir de la década de los 90 (con el asentamiento de la Cañada Real como caso paradigmático) pasa a ser predominantemente una táctica utilizada por minorías étnicas y migrantes sin papeles, que enfrentan una situación extrema de estigmatización y exclusión social (Gonick 2015, 1231). Este cambio de modelo nos lleva a preguntarnos en qué medida las conceptualizaciones en torno a la periferia deben desplazarse hacia la noción de "frontera" para adecuarse a estos procesos que abren un espacio liminal hacia una posible demarcación radical (Bou 2018,18).

Los estudios críticos de fronteras (Mezzadra y Neilson, 2013) dejan atrás los abordajes dicotómicos que las identifican con un muro infranqueable para estudiar los espacios liminales y ambiguos en los que se despliega la frontera, que es tan simbólica como material, y que ya no puede reducirse a una línea trazada geográficamente. Esta aproximación nos ayuda a superar la dualidad tajante entre dentro-fuera, centro-periferia, para precisamente problematizar la construcción de definiciones fijas (Mezzadra y Neilson, 2013:21). El espacio extremo que ocupa la Cañada Real en Madrid constituye un espacio de excepción, en continua redefinición y confrontación, una suerte de "aparheid legal" (Roy 2005,148) que nos lleva a conceptualizarlo desde la "fronterización" de la periferia.

Como periferias, estas geografías pueden brindar la posibilidad de un "derecho a la ciudad" (Harvey 2008), como fronteras, son espacios liminales de conflicto que dibujan un 
horizonte en constante amenaza de desplazamiento (Bou 2018, 18). La "fronterización" de la periferia supone atender a la conformación de espacios de "inconmensurable contradicción" (Gupta y Ferguson 1992, 18), espacios a un tiempo entre la esperanza, la incertidumbre, o incluso la distopía (Bou 2018, 6).

\section{La materialidad de las fronteras}

En esta segunda parte del artículo abordaremos el caso de la Cañada Real a través de cuatro elementos que le dan forma: los sucesivos diseños urbanos, los bolardos, el barro y los escombros. Cada uno de estos elementos despliega una dimensión diferente que nos permite ensayar la caracterización de la Cañada Real como espacio límite. A través de ellos nos aproximaremos a la transformación material y conceptual de la periferia en frontera.

\section{Los sucesivos diseños urbanos: desorden y almacén de pobreza}

La Cañada Real tiene unas características jurídicas muy peculiares como suelo demanial, pues las vías pecuarias son bienes de dominio público y por tanto "inalienables, imprescriptibles e inembargables". Esto significa que no se pueden ocupar, vender, regalar, ni están sujetas a normas de usucapión, es decir, a la prescripción de los derechos de propiedad de los bienes pasados 30 años de uso ajeno (Fariña 2009). Esta calidad del suelo, unida a años de dejadez institucional y una gran presión habitacional, resultó con la ocupación de un suelo que era "de todos" sin que nadie se opusiera.

La parcelación en la Cañada Real comenzó en la década de 1960 (Franchini 1988) aunque, como hemos visto, no fue hasta principios de 1990 y durante la década de los 2000 cuando se intensifica la ocupación y la construcción de edificaciones, aumentando la densidad y el uso residencial permanente (Secretariado Gitano 2011) coincidiendo con la creciente llegada de personas migrantes y también de personas desalojadas de otros asentamientos sin alternativa habitacional. La Cañada Real se fue convirtiendo en el lugar al que llegaban aquellos que no tenían a donde llegar.

También sirvió como estrategia política para que los realojos más conflictivos quedaran fuera de la vista, "un cómodo almacén en el que Madrid podía almacenar su exceso de pobreza" como relata con ironía Sophie Gonick $(2015,1231)$. Al igual que ocurrió a mediados de los años 90 durante el desmantelamiento de "los Focos", uno de los asentamientos más grandes de la época. El Partido Popular, que gobernaba por aquel entonces la Comunidad de Madrid, propuso la reubicación de 100 familias gitanas en el sector VI de Cañada, junto al vertedero de Valdemingómez, lugar en el que se tratan los residuos urbanos de la ciudad de Madrid. Las dimensiones raciales de esta actuación quedaron patentes en artículo en El País (1994) titulado "Un gueto en la Cañada" donde se hablaba directamente del racismo y la discriminación inherentes al proceso (Gonick 2015, 1231). Sin embargo, en este caso, el escándalo que acompañó esta decisión hizo que la actuación no siguiera adelante después de haber comenzado a reubicar ya a las familias.

Fue en estos años, cuando se aprobó una legislación específica para regir las vías pecuarias (estatal en 1995 y autonómica en 1998) estableciendo las bases para que las comunidades autónomas "defiendan su integridad, protección y conservación". De este modo 
se garantizaba el uso público de esta red de caminos tanto para facilitar el tránsito ganadero como para otros usos compatibles o complementarios (senderismo, cicloturismo o rutas a caballo). Pese a ello la Cañada siguió creciendo, y con ella la dificultad de encontrar una solución. Durante el final de la década de los 90 y principio de los 2000 continuó llegando población al asentamiento principalmente de origen marroquí, muchos de los cuales vinieron a trabajar en la construcción, ya que Madrid estaba en pleno desarrollo urbano (Universidad Autónoma de Madrid et al. 2004, 342).

Ante la complejidad de encontrar una solución, debido a las dimensiones que había adquirido el asentamiento, a los muchos intereses que se daban entorno a él, así como a la compleja articulación institucional que requeriría dicha solución, en 2011 las instancias políticas deciden desafectar íntegramente el tramo de Cañada que nos ocupa. A pesar de que el texto reconoce que la Cañada Real Galiana forma parte del "valioso patrimonio común", afirma que la vía "ha sufrido un fuerte declive propiciado por el intrusismo agrícola, residencial e industrial". Como consecuencia, un bien que era de dominio público pasa ahora a tener la condición de bien patrimonial y, por tanto, la Comunidad Autónoma de Madrid puede disponer de ellos para enajenarlos, cederlos o permutarlos. En ese momento ya estaba conformada la gran huella constante de $15 \mathrm{~km}$ de largo con más de 10 mil habitantes ${ }^{1}$.

En 2014 se intentó un Acuerdo Marco sin mucho éxito y en mayo de 2017 finalmente se firmó el Pacto de la Cañada que por fin reunía a todos los agentes políticos implicados (Ayuntamiento de Coslada, Ayuntamiento de Madrid, Ayuntamiento de Rivas Vaciamadrid y la presidenta de la Comunidad de Madrid). El pacto acordó la regularización y consolidación de los sectores más antiguos I y II, poblados principalmente por el éxodo rural en la década de 1960 y que presentan gran continuidad con el tejido adyacente. La demolición de los sectores III y VI, consolidados en la década de 1990 en adelante principalmente por la llegada de migración internacional, se prevén reubicaciones solo para las personas censadas hasta 2011. Los sectores IV y V aún siguen en suspenso y a la espera de un consenso en el momento en el que se redacta este texto.

\section{Los bolardos: presión urbanística y segregación}

La Cañada Real, que había permanecido salvo breves excepciones a la sombra del foco mediático, en 2007 llenó los titulares de los periódicos principales. La prensa se hacía eco de los enfrentamientos entre los vecinos y la policía por las órdenes de derribo que habían llegado al territorio. Esta confrontación violenta y visible parecía un paso obligado para llevar a cabo una estrategia de borrado. "Una Comunidad 'de vanguardia' como Madrid que es 'la número uno de España económicamente y una de las primeras de Europa' no podía permitirse un 'lastre' como ha sido desde hace años la Cañada Real para la región" (Esperanza Aguirre en El País 2009). La Cañada, para la entonces presidenta de la Comunidad de Madrid, era un "lastre", algo que entorpece el avance y el progreso de Madrid, en un

1 No hay consenso sobre la cifra exacta de habitantes. El censo de 2011 cifra en 8.628 las personas registradas, presumiblemente esta cifra sea bastante superior si sumamos las no registradas. El informe de Secretariado Gitano de 2011 da la cifra de 10.000, pero algunos medios como ABC (2011) publican cifras en torno a los 40.000 . 
momento en el que la capital se situaba en el ranking de las cinco ciudades líderes en el marco europeo.

Madrid se encontraba inmersa en una escalada hacia el crecimiento y el posicionamiento internacional sostenido en grandes operaciones de transformación urbana (Observatorio Metropolitano 2007, 288). En la periferia, una gran operación inmobiliaria llamada los desarrollos del "sureste" que pretendía construir más de 100 mil nuevas viviendas en cinco promociones de El Cañaveral, Los Cerros, Los Ahijones, Los Berrocales y Valdecarros. La Cañada Real quedaba literalmente rodeada y la mayor parte de su recorrido quedaba sobre el territorio colindante de los futuros desarrollos.

El colectivo de arquitectura de guerrilla Todo por la Praxis (citado en Álvarez-Agüí 2013) vincula los desarrollos urbanísticos con la aparición de presiones en el territorio y la agilización de cambios en el objeto legal que conformaba la Cañada que condujeron a la desafectación. Con esa decisión se cerró la posibilidad de recuperar su calidad ecológica como vía pecuaria y, a la vez, se colocó en una situación de mayor vulnerabilidad a los asentamientos, teniendo en cuenta los intereses económicos que había en la zona por la fuerte presión urbanística. Los promotores de las nuevas viviendas, presumiblemente, no querían tener la Cañada Real de vecina ya que ello afectaba al valor de sus nuevas viviendas. Sin embargo, si la Cañada terminaba absorbida por los nuevos proyectos en marcha podría computar como zonas verdes, mejorando la potencial plusvalía.

En nuestras derivas por los distintos sectores III, IV y V de la Cañada Real pudimos registrar ampliamente la presión urbanística. Diversos bolardos hormigonados al suelo dificultaban a los vecinos del sector $\mathrm{V}$ transitar desde la vía principal a una de las calles que conectaba con Rivas Vaciamadrid. Una situación similar nos encontramos en el perímetro del desarrollo de los Ahijones, donde tan visibles son los intentos de los vecinos de la Cañada para crear accesos a la zona recién asfaltada, como los bloqueos mediante contenedores de obra o bloques de hormigón por parte del Ayuntamiento de Rivas-Vaciamadrid, entre otros. También en el desarrollo del Cañaveral levantaron una valla que recorre todo el perímetro en contacto con la Cañada, impidiendo por completo las conexiones. Al otro lado de la valla, un paisaje de grúas, cableado, alumbrado público, alcantarillado y grandes movimientos de tierras va dibujando las futuras grandes vías que contrastan con la pequeña escala de la Cañada. También contrastan los trazos de diseños abstractos que se interrumpen abruptamente, sin dejarse afectar por la presencia de la huella serpenteante de la Cañada. La ciudad planificada y ordenada que está por llegar en su encuentro con el "desorden".

Las lógicas territoriales de "fronteras revanchistas" (Smith 1996) se hacen materiales en la Cañada Real en forma de bolardos, vallas o bloques de hormigón que materializan la segregación. Estos elementos, marcan físicamente un límite y evitan deliberadamente el contacto. También materializan la alteridad, que identifica a los vecinos de Cañada con un "otro" no bienvenido, con el que hay que poner distancia. Pero el bloqueo de las posibles conexiones también aísla y limita la capacidad de acceso a dotaciones públicas de los barrios vecinos o al acceso al transporte público, y deja como única alternativa el uso de la polvorienta vía central sin asfaltar que atraviesa como una espina dorsal la Cañada. 


\section{El barro: falta de infraestructura, suciedad y estigma}

De los seis sectores que componen la Cañada Real, solo los dos primeros tienen la vía asfaltada, obra que autogestionó el vecindario. "El barro es un distintivo de Cañada" del mismo modo que lo era en Orcasitas a finales de la década de los 50, cuando la asociación de vecinos escribió sobre el imaginario en torno al barro en un libro titulado "Del barro al barrio" (Martín et al. 1986). En los términos de R., una psicóloga comunitaria que trabajaba en la Cañada Real:

"Cuando no llueve, se levanta muchísimo polvo, se respira el polvo, se te ensucia la ropa... Todo. Es una sensación muy desagradable y agobiante. Y cuando llueve, toda la calle se embarra, se hacen charcos enormes. Es muy complicado circular por ahí. Y claro, te deja completamente incomunicado. Esto es un problema para los niños con el acceso al cole. Muchos viven lejos de donde les recoge la ruta escolar y no pueden llegar con el coche. También pasa mucho que llegan llenitos de barro a clase (...) y en el centro educativo, los profesores, muchas veces no lo entienden. No es que salgan sucios de casa, es que es imposible mantenerse limpio. El barro es un distintivo de Cañada. Nosotros siempre bromeamos con eso cuando nos manchamos las botas de barro, pero para los niños no es fácil, genera mucho estigma".

A la falta de mantenimiento de la vía central, se suma el abandono de las instituciones como proveedores de servicios básicos como son los servicios de recogida de basuras y de regulación de vertederos ilegales. Una vecina del sector $\mathrm{V}$ entrevistada, madre de cuatro niños, señalaba un reclutamiento en el interior de las parcelas por una sensación de inseguridad con respecto de las condiciones de salubridad y la falta de higiene. "Me preocupa la suciedad que tenemos donde los niños juegan, porque son niños, y hay mucha suciedad. Nos dicen que somos nosotros, pero nosotros somos muy limpios, nosotros queremos que esté limpio, (...) pero luego llegan esos camiones llenos de basura y nos lo dejan aquí, a la puerta de casa, en cualquier sitio, (...) y eso trae mucho olor y ratas, pero eso viene de fuera, no es basura nuestra" (M., vecina sector $\mathrm{V}$ ).

Como podemos entender de estas palabras, podrían estar desarrollándose vertidos ilegales de residuos en solares de la Cañada, cuestión que puede estar dificultando la convivencia y agravando la estigmatización de los vecinos de Cañada por las condiciones de salubridad y falta de higiene en el territorio. Es significativo en el fragmento la contraposición entre el "nosotros" y la acción de unos otros amenazantes de fuera, que traen basura y desprestigian al barrio. Expresa la capacidad de enunciarse como un sujeto colectivo, aunque sea un sujeto que se conjuga a la defensiva, en respuesta a las prácticas de discriminación y descrédito.

A la estigmatización encarnada por el barro y la suciedad se suma la mediática. Un año después de que la Cañada saltara a los periódicos, la televisión pública (RTVE) emitió un conocido documental sobre el asentamiento titulado "Ciudad sin ley". En él se presentaba una realidad homogéneamente chabolista, en conflicto con la policía, dominada por la droga y el caos. A este documental le siguieron un sinfín de noticias en los dos principales periódicos que hemos analizado (El País y El Mundo), que tuvo su punto álgido en el 2011, año en el que se publicaban más de una noticia a la semana sobre la Cañada (Morado 2017). En ellas encontramos de manera reiterada identificaciones a Cañada como "foco 
contaminante", "zona de guerra", "camping yonqui" o "ciudad prohibida". En ningún caso se retrata a los habitantes de Cañada como actores o sujetos políticos con capacidad de agencia que realicen actividades diferentes a las criminales. Se presenta al lugar como un paisaje distópico donde "niños que juegan entre ratas, van sucios al colegio y apenas se integran", donde habitan "nómadas entre deposiciones, basura, ratas, serpientes y una violencia enorme" (Morado 2017, 77).

La representación mediática racializada, con alusiones recurrentes al componente gitano o magrebí de su población, unida a la simplificación de la diversidad que habita en la Cañada Real a una imagen criminalizada y "yonqui", está sirviendo como vehículo de profundización del estigma y la marginación. Frente a considerar a la población víctima de las políticas y la dejadez, se les presenta como delincuentes que quieren vivir a costa de un bien común que es de todos (Monreal 2017, 142). Ofreciendo los argumentos para un borrado violento del territorio como el desarrollado a partir de 2007.

\section{Los escombros tras un derribo: amenaza y riesgo}

Disciplina Urbanística ejecutó más de 200 derribos en viviendas habitadas entre 2007 y 2012, que fueron paralizados por orden del Tribunal de Derechos Humanos de Estrasburgo tras una intensa lucha vecinal. Pero las amenazas volvieron en 2016 y, tras el acuerdo de 2017, se han vuelto a producir algunos casos de derribos con irregularidades en su procedimiento (Europa Press 2019).

"Los derribos son muy violentos, (...) los del ayuntamiento mandaron allí (señalando una casa) cuatro operarios con cuatro excavadoras y dos coches patrulla. (...) Y estaban a punto de meter la uña en casa de mi vecina y ella había salido a trabajar temprano, su hijo estaba aún durmiendo y casi lo tiran con el hijo dentro." (JK. vecino sector I-II).

A pesar de que los derribos han formado parte de forma intermitente en estos años, las historias, así como los escombros en los solares, han servido de recuerdo permanente de los violentos procesos de derribo y desalojo forzoso sufridos. Una vez se procede al derribo, comenta un vecino, "los escombros de las casas derribadas se quedan siempre ahí, para que todos vean como pueden terminar sus casas, para que cada vez que lo veas te recuerde cómo puede terminar tu casa, (...) es muy duro eso" (H., vecino sector $\mathrm{V}$ ).

Los derribos contribuyen a precarizar las condiciones materiales de las personas desalojadas. A menudo tienen como única alternativa volver a levantar una construcción en el solar junto a los escombros de su antigua vivienda y enfrentarse a una situación de endeudamiento permanente por no poder hacer frente a los gastos que la demolición conlleva (Álvarez-Agüí 2017, 226). Rompen lazos vecinales al producir desplazamientos, así como deterioran el entorno, generando espacios de riesgo donde se acumula materiales cortantes y punzantes, cableado y tuberías al aire, degradando aún más las condiciones higiénicas y poniendo en riesgo al vecindario.

Los escombros sirven de testigo y amenaza del futuro que les espera a las personas que habitan en el territorio de la Cañada. Conforman un límite temporal que condiciona a vivir un presente amenazado y que erradica la posibilidad de imaginar un futuro distinto del derribo, también cierran la posibilidad de escapar de la espiral del desplazamiento. 


\section{Conclusiones}

Si la Cañada Real señala los límites de Madrid no es solo porque a lo largo de sus $15 \mathrm{~km}$ se entrecrucen los bordes de varios de sus municipios ni porque se sitúe geográfica y socialmente en la periferia. La Cañada Real expresa los límites del modelo urbano madrileño, exponiendo el modo en el que sus lógicas de organización suponen una crisis interna (por más que trate de ser expulsada hacia fuera) y su supuesto éxito entraña un fracaso. El asentamiento que durante más de 60 años ha ido consolidándose sobre la vía pecuaria es algo más que una "consecuencia no deseada" de años de crecimiento de la capital; es el signo inequívoco de las contradicciones, conflictos y violencias que ese crecimiento implica. La afirmación de este límite, en un momento en el que existen varias operaciones urbanísticas en sus márgenes, bien podría representarse con el encogimiento de hombros ("a casual shrug") con el que Ananya Roy $(2005,156)$ caricaturiza la incapacidad de la planificación por abordar los complejos sistemas sociales a través de los cuales se debe implementar.

La situación de la Cañada Real como vía pecuaria y el carácter demanial de su suelo, tan poco común dentro de las normas e instituciones urbanas, asentó las condiciones de existencia de ese espacio de excepcionalidad en la ciudad de Madrid. Lo que en un principio servía funcionalmente a la gran ciudad como "cuarto de atrás": gran almacén, mercado de prácticas alegales e ilegales y acumulación de residuos en situación de cierta permisividad; fue cumpliendo simultáneamente la tarea de "amortiguación" de la pobreza sobre el desarrollo de un tejido abandonado por las infraestructuras y las dotaciones públicas. Esta ciudad "sin ley" o, más bien, "sin ciudad" convocaba así una diversidad de intereses encontrados, de tensiones sociales que se amalgamaron en la urbanización del límite urbano, precisamente donde la ciudad deja de ser ciudad. En sintonía con la filósofa Wendy Brown (2010), vemos a la Cañada Real como parte de un proceso de proliferación de fronteras más o menos sutiles características del mundo contemporáneo y que constituyen un síntoma más de la crisis de modelo urbano. La tesis de Brown es aquí especialmente pertinente porque incide en la importancia las fronteras como espacios de indefinición "entre la ley y la falta de ley" (Brown 2010,16-17) que resulta tan productiva para los órdenes urbanos canónicos.

En primera instancia, en este artículo nos hemos aproximado a las particularidades jurídicas que presenta el caso de estudio. Su evolución histórica permite reflexionar sobre cómo se definen las políticas urbanas y, especialmente, sobre cómo estas se asientan en un sistema de legitimidad que decide qué es ciudad y cuáles son sus límites, qué vidas merecen ser mantenidas y cuáles pueden permanecer en la espiral de los desplazamientos. Los derribos nos muestran un modo de entender la ciudad y, por tanto, de aquello que puede construirse o derribarse legítimamente. Como otros espacios informales, la Cañada Real se diseña como la excepción de la planificación, así como también exprese el límite del ámbito de control por parte del Estado. Se trata de un lugar jurídico de excepcionalidad, en constante diseño, redefinición y creación de estados de ambigüedad legal. Traerla al frente nos lleva a visibilizar cómo el aparato de planificación también produce lo no planificado (Roy 2005, 155-156).

En segundo lugar, el conocimiento situado desde las fronteras nos permite descubrir dinámicas multiescalares que se despliegan en prácticas y materialidades concretas. El análisis de la estructura del territorio y las derivas han facilitado explorar las tensiones y los 
conflictos que conforman la frontera. El territorio de Cañada en su paso por los sectores III, IV y VI está atravesado y delimitado de fronteras sutiles que segregan el propio espacio por medio de vallas y bolardos, levantando obstáculos a la movilidad cotidiana de los habitantes y componiendo un paisaje de discriminación entre la ciudad "adecuada" y la que es negada. Estos procesos de segregación dialogan con operaciones de especulación en el entorno próximo que han amenazado y amenazan importantes tramos de la vía. Una frontera se dibuja en el encuentro abrupto entre los dos tejidos urbanos: el tejido orgánico de la delgada "ciudad lineal informal" (Franchini, 1988) y el tejido de cuadrícula abstracta de los nuevos desarrollos de infraestructura sobredimensionada.

Ligado a estas balizas de señalamiento y segregación, y como tercer punto de análisis, se ha expuesto el trabajo productivo de la frontera en términos simbólicos (y no por ello, sin un sustrato material) como fuente de estigma sobre el espacio y sus habitantes. El barro de las calles no asfaltadas, el olor a la basura que de manera ilegal se vierte en las calles levantan un escenario que se queda pegado a la imagen que se proyecta sobre el vecindario. Así como los niños de la Cañada son identificados en el colegio por la suciedad de sus zapatos, la representación social de la zona lleva indefectiblemente un imaginario de contaminación ambiental y moral de drogas, basura, barro o ratas. La ciudad se constituye en relación con un "otro" externo que le permite dibujar sus límites mediante procesos de constitución de subjetividades frente a aquello que se deja "fuera", lo que Julia Kristeva denomina "lo abyecto" (2006).

La separación física, que dificulta la entrada de los habitantes de la Cañada a otros barrios, supone y se sostiene por tanto en una separación simbólica, fuertemente productiva en el largo plazo como justificación de la injerencia de los poderes públicos. La estigmatización de los habitantes sirve como herramienta para abrir el camino al borrado del territorio. En una dirección similar, Wacquant (2007) afirma que la estigmatización es una de las expresiones más claras de la expropiación simbólica y, por lo tanto, de violencia simbólica ejercida sobre los más desfavorecidos. La representación del tejido urbano bajo la imagen de un territorio habitado por sujetos criminalizados no dirige el discurso a la eliminación de la pobreza o de sus causas estructurales, sino a la erradicación de aquellas formas de vida que no llegan a alinearse con el proyecto urbano (social, político y económico) dominante (Álvarez-de Andrés 2020, 8).

Así, el único espacio de posibilidad que se dibuja desde las instituciones es la demolición. El cuarto elemento analizado, los escombros, remite a esa última frontera temporal, como una separación drástica entre un presente en constante reinicio y un futuro negado. El derribo se presenta como la única herramienta urbanística válida en la relación que la ciudad establece con lo informal. Los fragmentos de casas en los solares del paisaje urbano de la Cañada quedan como una señal de amenaza sobre el presente y como aviso sobre el posible futuro. Este sentido de límite en tanto que erradicación de futuro puede relacionarse tanto con lo que el filósofo Achille Mbembe (2003) llama "necropolítica", como con lo que el antropólogo Arturo Escobar llama "desfuturización" (2016). La frontera temporal se dibuja como proceso biopolítico que contribuye a invisibilizar, precarizar, e incluso en ocasiones erradicar, las subjetividades que quedan en los márgenes. La Cañada Real queda fijada en esos "espacios grises", entre la blancura de la legalidad (la aprobación y 
la seguridad) y la negrura del desalojo y la destrucción como modo de "solucionar" el problema de la marginalidad (Yiftachel 2009, 92).

A través del estudio de los sucesivos diseños urbanos de los que ha sido objeto la Cañada Real y la presión urbanística en sus márgenes, hemos podido constatar cómo se constituye un "espacio límite", que es simultáneamente material, simbólico y temporal: la ciudad formal, planificada y ordenada, representativa del desarrollo urbano, en su encuentro con el "desorden". Las fronteras no son solo una descripción geográfica, ni un desvío de las normas o del canon urbano, como expresa la antropóloga Anna Tsing $(1994,279)$, son un lugar analítico que hace evidente lo constreñido y opresivo de la cualidad de exclusión y, a la vez, el potencial creativo de su rearticulación. Situarnos en la frontera nos ha permitido abrir una mirada crítica hacia las configuraciones urbanas marginadas y a las tensiones entre dominación y resistencia que en ella se dan. Teresa Caldeira $(2016,4)$ nos insta a entender las formas de la urbanización periférica no solo para formular mejores análisis y teorías, sino también para mejorar nuestras prácticas de planificación. Esto pasa por entender tanto los órdenes, como los desórdenes que construyen, y con los que construimos, nuestro mundo urbano.

\section{Bibliografía}

Aguilera, Thomas. 2017. Gouverner les illégalismes urbains. Les politiques publiques face aux squats et aux bidonvilles dans les régions de Paris et de Madrid. Dalloz, Paris.

Alguacil Gómez, Julio, Concha Denche Morón, Agustín Hernández Aja, Concha León, Isabela Velázquez Valoria, y Tomás Rodríguez Villasante. 1989. Retrato de chabolista con piso : Análisis de redes sociales en la remodelación de barrios de Madrid. Editado por Javier Echenagusia y Pedro Gómez. Madrid: E.T.S. Arquitectura (UPM). http://oa.upm.es/14695/.

Álvarez Agüí, Nuria. 2017. «Formulación y tratamiento de un "problema social": en torno a los desalojos forzosos en la Cañada Real (Madrid)». AIBR: Revista de Antropología Iberoamericana 12 (2): 215-39.

Álvarez-de Andrés, Eva. 2020. «Necropolítica de vivienda: 40 años desmantelando la "informalidad" en Madrid (1979-2019)». Eure 46 (139): 5-27.

Bou Akar, Hiba. 2018. For the war yet to come: Planning Beirut's Frontiers. Stanford, California.

Brenner, Neil. 2013. «Theses on Urbanization». Public Culture 25 (1): 85-114. https://doi.org/10.1215/08992363-1890477.

Brown, Wendy. 2010. Walled States, Waning Democracy. Nueva York, Zone Books.

Caldeira, Teresa. 2000. City of Walls: Crime, Segregation, and Citizenship in São Paulo. University of California Press.

Caldeira, Teresa. 2016. «Peripheral Urbanization: Autoconstruction, Transversal Logics, and Politics in Cities of the Global South»: Environment and Planning D: Society and Space, julio. https://doi.org/10.1177/0263775816658479. 
Carabancheleando. 2017. Diccionario de las periferias: métodos y saberes autónomos desde los barrios. 1a edición. Útiles 19. Madrid: Traficante de Sueños.

Carmona, Pascual, y Emmanuel Rodríguez López. 2007. «Barrios: planificación, inmigración y movimiento vecinal (1939-1986)». En Madrid, ¿la suma de todos?, editado por Metropolitano Observatorio. https://www.traficantes.net/libros/madrid$\%$ C2\%BFla-suma-de-todos.

Castells, Manuel. 1983. The City and the Grassroots. A Cross-Cultural Theory of Urban Social Movements. University of California Press.

Davis, Mike. 2006. Planet of Slums. Verso.

Escobar, Arturo. 2016. Autonomía y diseño: la realización de lo comunal. Primera edición en castellano. Popayán, Colombia: Editorial Universidad del Cauca.

Europa Press. 2019. «Valdemingómez: comienza la mudanza de la Cañada Real Galiana». $a b c$, 9 de junio de 2019, sec. España. https://www.abc.es/espana/madrid/abcivaldemingomez-comienza-mudanza-canada-real-galiana201906100049_noticia.html.

Fariña, José. 2009. «Cañada Real Galiana, la vergüenza de Madrid». El Blog de José Fariña (blog). 44 de 4009. https://elblogdefarina.blogspot.com/2009/09/canada-real-galiana-la-verguenzade.html.

Franchini, María Teresita. 1988. «Una Ciudad Lineal Espontánea: La Cañada Real de Merinas». Ciudad y Territorio 75.

Ghannam, Farha. 2002. Remaking the Modern: Space, Relocation, and the Politics of Identity in a Global Cairo. University of California Press. https://www.ucpress.edu/book/9780520230460/remaking-the-modern.

Gonick, Sophie. 2015. «Interrogating Madrid's "Slum of Shame”: Urban Expansion, Race, and Place-Based Activisms in the Cañada Real Galiana». Antipode 47 (5): 1224-42. https://doi.org/10.1111/anti.12156.

Gupta, Akhil y James Ferguson. 1992. «Space, Identity, and the Politics of Difference». Cultural Anthropology, 7 no.1: 6-23.

Harvey, David. 2008. «The Right to the City». New Left Review 53: 23-40.

Holston, James. 1989. The Modernist City: An Anthropological Critique of Brasilia: Architecture, Politics and Society in Brasilia. Chicago.

Holston, James. 2009. «Insurgent Citizenship in an Era of Global Urban Peripheries». City \& Society 21 (2): 245-67. https://doi.org/10.1111/j.1548-744X.2009.01024.x.

Kristeva, Julia. 2006. Poderes de la perversión. Ensayo sobre Louis-Ferdinand Céline. Siglo XXI. Martín Amoriaga, Tomás, y Asociación de Vecinos de Meseta de Orcasitas. s. f. Del barrio al barro. 1986.

Martínez, Miguel Ángel, y Ángela García. 2015. «Ocupar las Plazas, Liberar Edificios (The Occupation of Squares and the Squatting of Buildings)». ACME: An International Journal for Critical Geographies 14 (1): 157-84.

Mbembe, Achille. 2003. «Necropolitics». Public Culture 15 (1): 11-40. https://doi.org/10.1215/08992363-15-1-11. 
Mezzadra, Sandro y Neilson, Brett. 2017. La frontera como método. Traficantes de Sueños. https://www.traficantes.net/sites/default/files/pdfs/PC15_frontera_como_metodo_ 2.pdf.

Monreal Requena, Pilar. 2017. «Intervenciones públicas en las periferias del sureste madrileño». Arxiu d'Etnografia de Catalunya 17: 137-54. https://doi.org/10.17345/aec2017137-154.

Morado, Candela. 2017. «En los límites de la ciudad: El caso de la Cañada Real Galiana de Madrid». Territorios en formación 0 (11): 67-84. https://doi.org/10.20868/tf.2017.11.3460.

Mouffe, Chantal. 2000. The democratic paradox. New York: Verso.

Nogues Sáez, Luis José. 2010. «Exclusión residencial y políticas públicas: el caso de la minoría gitana en España (1986-2006)». Universidad de Granada.

Observatorio Metropolitano. 2007. Madrid ¿la suma de todos? Globalización, territorio, desigualdad. Traficantes de Sueños. https://www.traficantes.net/libros/madrid$\%$ C2\%BFla-suma-de-todos.

Pinilla, Maria. 1994. «Un gueto en La Cañada». El País, 17 de junio de 1994, sec. Madrid. https://elpais.com/diario/1994/06/18/madrid/771938675_850215.html.

Europa Press. 2019. «La Justicia condena al Ayuntamiento de Madrid por demoler la casa de una familia de La Cañada "sin autorización"». ElDiario.es. 5 de junio de 2019. https://www.eldiario.es/desalambre/justicia-condena-ayuntamiento-canadaautorizacion_1_1520027.html.

Robinson, Jennifer. 2005. Ordinary Cities: Between Modernity and Development. London ; New York: Routledge.

Roy, Ananya. 2005. «Urban Informality: Toward an Epistemology of Planning». Journal of the $\begin{array}{lllll}\text { American } & \text { Planning } & \text { Association } & 71 & \text { (2): }\end{array}$ https://doi.org/10.1080/01944360508976689.

Roy, Ananya, y Nezar Alsayyad, eds. 2004. Urban informality: Transnational Perspectives from the Middle East, Latin America, and South Asia. Lexington Books.

Sambricio, Carlos. 1999 «La vivienda social en Madrid en la década de los 50: el Plan de Urgencia Social». Madrid: Ministerio de Fomento y Gerencia de Urbanismo.

Secretariado Gitano. 2011 «Informe Social de la Cañada Real Galiana: Programa de Intervención»

Simone, AbdouMaliq. 2004. For the City Yet to Come: Changing African Life in Four Cities. Durham: Duke University Press.

Simone, AbdouMaliq. 2007. "At the frontier of the urban periphery». En Sarai Reader, 46270. 07, Frontiers. Dehli: Centre for the Study of Developing Societies.

Smith, Neil. 1996. The New Urban Frontier : Gentrification and the Revanchist City. Routledge. https://doi.org/10.4324/9780203975640.

Tsing, Anna L. 1994. «From the margins». En Cultural Anthropology 9(3):279-297. American Anthropological Association.

Universidad Autónoma de Madrid et al. 2004. «Atlas de la inmigración marroquí en España.» Madrid. 
Vorms, Charlotte. 2003. «La urbanización marginal del extrarradio de Madrid: Una propuesta espontánea al problema de vivienda» Scripta Nova, VII, núm. 146 (13). Universidad de Barcelona.

Wacquant, Loïc. 2007. Los condenados de la ciudad: gueto, periferias, Estado. Buenos Aires, Siglo XXI.

Yiftachel, Oren. 2009. «Theoretical Notes On 'Gray Cities': The Coming of Urban Apartheid?» Planning Theory, febrero. https://doi.org/10.1177/1473095208099300.

Zeiderman, Austin. 2016. Endangered City: The Politics of Security and Risk in Bogotá. Duke University Press. https://doi.org/10.1215/9780822374183.

(C) Copyright: Candela Morado, 2021

(C) Copyright: Scripta Nova, 2021.

Ficha bibliográfica:

MORADO, Candela. La fronterización de la periferia urbana de Madrid. Scripta Nova.

Revista Electrónica de Geografía y Ciencias Sociales. Barcelona: Universitat de

Barcelona, vol. 25, Núm. 2 (2021), p. 57-73 [ISSN: 1138-9788]

DOI: $10.1344 / \mathrm{sn} 2021.25 .32559$ 